\title{
VERIFICATION OF WEATHER CONDITION FOR HIGH WAVE AND STORM SURGE ESTIMATION DUE TO EXPLOSIVE CYCLONE
}

\author{
Takuto Haga, Chuo University, a13.jinp@g.chuo-u.ac.jp \\ Kazuhiro Fujiwara, Chuo University, a14.xr7a@g.chuo-u.ac.jp \\ Katsumi Seki, Chuo University, seki-k.15e@g.chuo-u.ac.jp \\ Taro Arikawa, Chuo University, arikawa.38d@g.chuo-u.ac.jp
}

\begin{abstract}
INTRODUCTION
There is concern that the disaster risk of high wave and storm surge due to explosive cyclone is increasing around Japan with the global warming as a cause. When studying the disaster prevention of high wave and storm surge, high wave and storm surge estimation is a cogent means. In order to maintain higher estimation accuracy, reproducibility of weather field as external force condition is important. Even among them, the accuracy of empirical weather model is important for probabilistic risk assessment for waves and storm surges. However, there are few examples to apply empirical weather model to explosive cyclone. Therefore, we applied empirical typhoon model to explosive cyclones and the applicability to wave and storm surge estimations is verified.
\end{abstract}

\section{WEATHER CONDITION}

Two explosive cyclones are considered as objects. Also, a typhoon case is added to compare between the types of weather disturbances. Furthermore, to compare between methods, the method that GSM weather data set is interpolated linearly is done for each case. In one method-1, the empirical typhoon model and the radius extracted from the data set are used, while in method-2, the GSM data set is linearly interpolated timewise and spatially.

\section{WAVE AND STORM SURGE ESTIMATION}

Wave simulator is SWAN and storm surge simulator is STOC-ML. Figure 1. shows the Comparison between calculated and observed maximum values of significant wave height, mean wave period and storm tide at observation points. Table 1 . shows the correlation coefficients ( $r$ ) and slope of regression line (a) between the calculated and observed values of significant wave height, mean wave period and storm tide at all observation points.

\section{CONCLUSION}

When method- 1 is used, the correlation between the waves estimation / the storm surge estimation result of the typhoon case and the observation value is high. On the other hand, the wave estimate / storm surge estimate result for the explosive cyclone case is underestimated compared to the observation value. When method - 2 was used, it was confirmed that correlation was high in every case.


(a) Explosive cyclone in 2016
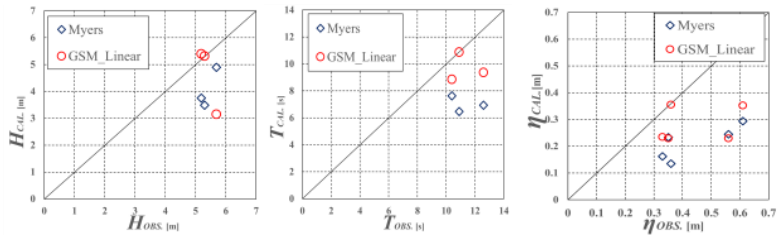

(b) Explosive cyclone in 2014
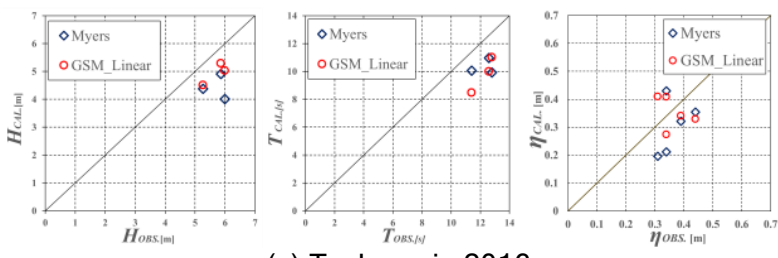

(c) Typhoon in 2016

Figure 1 - Comparison between calculated and observed maximum values of significant wave height, mean wave period and storm tide at observation points

Table 1 - Correlation coefficients and slope of regression line

\begin{tabular}{|c|c|c|c|c|c|c|c|}
\hline \multicolumn{2}{|c|}{} & \multicolumn{2}{|c|}{2016 Cy. } & \multicolumn{2}{c|}{ 2014_Cy. } & \multicolumn{2}{c|}{ 2016_Ty. } \\
\cline { 2 - 8 } & $\mathrm{a}$ & $\mathrm{r}$ & $\mathrm{a}$ & $\mathrm{r}$ & $\mathrm{a}$ & $\mathrm{r}$ \\
\hline $\begin{array}{c}\text { Significant } \\
\text { wave } \\
\text { height }\end{array}$ & Myers & 0.601 & 0.820 & 0.671 & 0.768 & 1.581 & 0.809 \\
\cline { 2 - 8 } & GSM & 0.792 & 0.921 & 0.831 & 0.726 & 1.082 & 0.944 \\
\hline $\begin{array}{c}\text { Mean } \\
\text { wave } \\
\text { period }\end{array}$ & Myers & 0.493 & 0.882 & 0.488 & 0.795 & 1.911 & 0.676 \\
\cline { 2 - 8 } & GSM & 0.845 & 0.793 & 0.800 & 0.787 & 1.435 & 0.368 \\
\hline $\begin{array}{c}\text { Mean } \\
\text { storm tide }\end{array}$ & Myers & 0.065 & 0.031 & 0.400 & 0.752 & 0.298 & 0.635 \\
\cline { 2 - 8 } & GSM & 0.774 & 0.904 & 0.464 & 0.649 & 0.871 & 0.591 \\
\hline
\end{tabular}

\section{ACKNOWLEDGMENTS}

The authors would like to thank Ports and Harbors Bureau, Ministry of Land, Infrastructure, Transport and Tourism for providing the wave data set (NOWPHAS) and Port and Airport Research Institute for processing the data set. The authors would also like to thank Mr. Y. Chida of Port and Airport Research Institute for providing insightful comments about STOC-ML.

\section{REFERENCES}

Myers, V. A. and Malkin, W. (1961): Some properties of hurricane wind fields as deduced from trajectories, U. S. Weather Bureau, National Hurricane Research Project, Report 4.

Ris, R. C., N. Booij and L.H. Holthuijsen, (1999): A thirdgeneration wave model for coastal regions, Part II, Verification, J. Geophys. Res. C4, 104, 7667-7681. Takashi T. and Taro K. (2005): Development of numerical simulator STOC for storm surge and tsunami considering three dimensionality of seawater flow and application to tsunami analysis [in Japanese]. Report of the Port and Airport Research Institute, PARI 44(2), 83-98, 2005-06. 